\title{
An Analysis of the Prominent Cultural Values of Asian People through Similar Folktales
}

\author{
Onusa Suwanpratest
}

\begin{abstract}
The objectives of this research are to determine the cultural values of Asian people through selected similar folktales, and to understand the characteristics of Asian lifestyles. Further research in this field may have applications in other branches of the social sciences. The scope of this study is limited to Asian folktales which contain a common motif related to snails, including transformation from man to snail or transformation from snail to man. A sample of six Asian folktales from Thailand, Myanmar, Indonesia, China, Korea, and Japan are selected, all of which contain the motif of snail transformations. In these tales, seven cultural values may be observed, namely, gratitude, good karma, supernatural believe, holy spirit, male dominance, inner virtue, and role of women and children. All of these cultural values were ranked in terms of their prominence. These cultural values reflect an idealized society of the past; however they continue to influence social values in the present, although they may not have the same level of influence as they did in the past. The outcomes revealed that the three most prominent cultural values in Asia are the supernatural beliefs, followed by gratitude and good karma, respectively. In conclusion, these shared values give a clearer illustration of the characters and perspectives of Asian people which ultimately lead to an understanding of the Asian way of life.
\end{abstract}

Index Terms-Asia, cultural values, folktales, shared values.

\section{INTRODUCTION}

Folktale is a cultural and traditional heritage handed down over time through the generations of members of a cultural community. For a long time, folktale was preserved only in the oral tradition; the written versions or records of evidence became available only after the advent of printing technology [1]. For this reason, it is almost impossible to trace the authorship of most tales, however, often it may be possible to trace the culture where the tales originated. Despite this lack, folktales still play important roles in the lives of people in all cultural communities. Through storytelling, it entertains people after a long day of routine work; it relieves social tension and provides instructions to cultural members. Most importantly, folktales mirror the cultural values held collectively by the people in each society [2].

Stith Thompson-an American scholar of folklore who developed the alpha-decimal motif-index system (A-Z followed by numeral) for cataloging individual motifs of folktales - indicates that folktales from around the world normally share certain contents, motifs and traits. Studies of

Manuscript received October 25, 2015; revised January 20, 2016

Onusa Suwanpratest is with the Department of Literature and Folklore, Faculty of Humanities, Naresuan University. Phitsanulok, 65000, Thailand (e-mail: onusas@nu.ac.th) similarities in world folktales may help us map this universal blueprint that is common to all human cultures [3].

In Asia, there is a group of folktales that interestingly shares the same narrative motif, namely, "the transformation of man to snail". This motif is catalogued as D198 in Stith Thompson's motif index [4]. An elaborate discussion of this motif can be found in Hiding in the Shell: a Comparative Study of Thai Folktale "Sang Thong" (The Golden Conch) and Similar Folktales in Asia [5]. The selected folktales are similar in motif. The motif is one where the protagonists hide in a shell, such as a snail or a conch, as they seek protection or camouflage while in danger or experiencing misfortune. Apart from their similarities in motif and plot, this group of folktales mirrors similarities in cultural values. However, Onusa Suwanpratest only explores components from five folktales from Thailand, Myanmar, Indonesia, China and Korea, which share the "hiding in the shell" motif. It is indeed a comparative study of the similarities and differences of the quoted folktales in Asia [Ibid]. Folktales are precious data which reflect the cultural values of the people of the time the stories were told [6]. There are some studies related to cultural values. Preeti Dhillon, in her paper [7] attempts to find common social values in peoples from Europe, Africa, the Americas and Asia. Dhillon's study uses data form various international studies to find common ground between cultures around the world. She hopes that her study would be helpful in enabling people to understand one another in the international political and economic arenas. Dhillon's study indicated that one of the Chinese values is that of Hard Work. See Hoon Peow, a Malaysian scholar, analyzed some Malaysian Chinese folk narratives and found that the social value of Hard Work is, likewise emphasized [8]. The results of these studies suggest that it is possible to study cultural values through the medium of folktales. This paper attempts to find and rank Asian social value systems through the medium of folktales.

This study analyzes the cultural values and ranks the significant features that appear in Asian folktales which share a common motif related to snail transformations. This would help understand through prominent characters the way of life of the people within the region at the time. The study also aims to provide a beneficial resource for further studies in other branches of social sciences such as education, advertising and tourism.

\section{OBJECTIVES}

The objectives for this project are:

1) To determine cultural values of Asian people as represented in selected folktales. 
2) To generate data that may be relevant to other social sciences such as education, advertising and tourism.

\section{MethodolOGY}

\section{A. Scope of Study}

The folktales in this study contain these related motifs, according to Thompson (1885) [9]: "D198 - transformation of man to snail" or "D398 - transformation of snail to man". The six sample tales are from six Asian countries, namely, Korea, Thailand, Myanmar, Indonesia, China, and Japan, as shown in the table below (see Table I):

TABLE I: THE SAMPLE OF ASIAN FOLKTALES, As LisTED ACCORDING TO COUNTRY

\begin{tabular}{llc}
\hline \hline & \multicolumn{1}{c}{ Name (abbreviation) } & Country \\
\hline 1. & The Snail Lady (SL) [10] & Korea \\
2. & Sung Tong (ST) [11] & Thailand \\
3. & The Snail Prince (SP) [12] & Myanmar \\
4. & Golden Snail (GS) [13] & Indonesia \\
5. & River Snail Girl (RSG) [14] & China \\
6. & A Snail Millionaire (SM) [15], & Japan \\
& {$[16]$} & \\
\hline \hline
\end{tabular}

\section{B. Analysis of CulturAl Values as Found in the Selected Folktales}

The cultural values in these Asian folktales were characterized according to the social values contained in each story. The components which are selected for consideration include title, origin, character, motif, plot, story, scenes, and message.

\section{Determining Prominent Cultural Values and Dominant Features}

After the cultural values in each folktale are determined according to item 2 above, the cultural values from the folktales are ranked according to the degree of prominence in each folktale. The ranking scale is based on the number of cultural values according to item 2 . The ranking of each cultural value was conducted using the ranking scale of 1-7 where 1 refers to the most prominent cultural value and 7 refers to the least prominent (see table III). The total sum of each cultural value is determined according to their references in the folktales. The most prominent cultural value is indicated by the lowest total sum of scores. The dominant features of the cultural values in each folktale are characteriezed using a similar method.

\section{RESULTS}

TABLE II: CULTURAL VALUES FROM THE ASIAN FOLKTALES SELECTED FOR THIS PROJECT

\begin{tabular}{|c|c|c|}
\hline & Cultural value & Sample Asian Folktale \\
\hline 1. & Gratitude (GT) & SL/ ST/ SP/ GS/ RSG/ SM \\
\hline 2. & Good Karma (GK) & SL/ ST/ SP/ GS/ RSG/ SM \\
\hline 3. & Supernatural Beliefs (SB) & SL/ ST/ SP/ GS/ RSG/ SM \\
\hline 4. & Holy Spirit (HS) & $\mathrm{ST} / \mathrm{SM} / \mathrm{GS}$ \\
\hline 5. & Male Dominance (MD) & $\mathrm{ST} / \mathrm{SM} / \mathrm{SP}$ \\
\hline 6. & Inner Virtue (IV) & SL/ ST/ SP/ RSG/ SM \\
\hline 7. & $\begin{array}{l}\text { Role of Women and Children } \\
\text { (WCh) }\end{array}$ & SL/ ST/ GS/ RSG \\
\hline
\end{tabular}

From the study of cultural values of Asian people through the sample folktales, we may arrive at the following outcomes (see Table II):

TABLE III: RANKING OF PROMINENT CULTURAL VALUES IN THE ASIAN FOLKTALES SELECTED FOR THIS PROJECT

\begin{tabular}{|c|c|c|c|c|c|c|c|}
\hline \multirow{2}{*}{ Sample Folktale } & \multicolumn{7}{|c|}{ Cultural Value } \\
\hline & GT & GK & SB & HS & MD & IV & WCh \\
\hline 1.Snail Lady (SL) & 2 & 5 & 1 & 7 & 6 & 4 & 3 \\
\hline 2.Sung Tong (ST) & 3 & 5 & 1 & 4 & 2 & 6 & 6 \\
\hline 3.Snail Prince (SP) & 5 & 2 & 1 & 6 & 4 & 3 & 7 \\
\hline 4. Golden Snail (GS) & 3 & 4 & 1 & 2 & 6 & 7 & 5 \\
\hline $\begin{array}{l}\text { 5.River Snail } \\
\text { Girl (RSG) }\end{array}$ & 2 & 5 & 1 & 7 & 6 & 4 & 3 \\
\hline $\begin{array}{l}\text { 6. Snail } \\
\text { Millionaire } \\
(\mathrm{SM})\end{array}$ & 3 & 5 & 1 & 2 & 4 & 6 & 7 \\
\hline
\end{tabular}

Note: GT, GK, SB, HS, MD, IV and WCh refer to Gratitude, Good Karma, Supernatural Beliefs, Holy Spirit, Male Dominance, Inner Virtue, and Role of Women and Children, respectively.

TABLE IV: TOP THREE DOMINANT CULTURAL VALUES IN THE ASIAN FOLKTALES SELECTED FOR THIS PROJECT

\begin{tabular}{llc}
\hline \hline & \multicolumn{1}{c}{ Sample Folktale } & Cultural Value \\
\hline 1. & Snail Lady (SL) & $\mathrm{SB} / \mathrm{GT} / \mathrm{WCh}$ \\
2. & Sung Tong (ST) & $\mathrm{SB} / \mathrm{MD} / \mathrm{GT}$ \\
3. & Snail Prince (SP) & $\mathrm{SB} / \mathrm{GK} / \mathrm{IV}$ \\
4. & Golden Snail (GS) & $\mathrm{SB} / \mathrm{HD} / \mathrm{GT}$ \\
5. & River Snail Girl (RSG) & $\mathrm{SB} / \mathrm{GT} / \mathrm{WCh}$ \\
6. & Snail Millionaire (SM) & $\mathrm{SB} / \mathrm{HS} / \mathrm{GT}$ \\
\hline \hline
\end{tabular}

Note: GT, GK, SB, HS, MD, IV and WCh refer to Gratitude, Good Karma, Supernatural Beliefs, Holy Spirit, Male Dominance, Inner Virtue, and Role of Women and Children, respectively.

\section{DISCUSSION}

From Table II, it is evident that the sample folktales contain these 7 values:

1) Gratitude (GT)

2) Good Karma (GK)

3) Supernatural Beliefs (SB)

4) Holy Spirit (HS)

5) Men Dominant (MD)

6) Inner Virtue (IV)

7) Role of Women and Children (WCh)

Gratitude is found in all of the sample folktales; therefore, it could be said that gratitude is valued by all of the represented Asian cultures. It should be observed that the protagonists in all these tales reward their benefactors in a similar manner. In the tales with the "transformation of man to snail" motif (Snail Lady of Korea, Sung Tong of Thailand, Snail Prince of Myanmar, Golden Snail of Indonesia, and River Snail Girl of China), the protagonists hide in the shell to escape from danger, but they leave the shell to clean the house and cook dinner for their benefactors. In A Snail Millionaire of Japan, which contains the "transformation of snail to man" motif, the hero is born a snail and is later transformed into a human being. The hero later obtains wealth through trade and repays his benefactors by looking after them in old age.

The belief in karma is another value that appears in all of the sample folktales. Karma is the belief that whatever you do, for best or for worse, comes back to you [17]. Therefore, it could be said that all represented Asian cultures believe that a 
virtuous person will never face a tragic end. Even in hard times, a virtuous person will always find needed helpp. The prince in Sung Tong is born as a conch shell, and the King's minor wife accuses him of bringing bad luck. The prince and his mother are banished from the kingdom, but they are rescued by an old farmer couple who give them a new home. In Golden Snail, the King of Antah Berantah lays eyes on Dewi Sekartaji and kidnaps her from her husband, Raden Panji Asmoro Bangun. The god Batara Narada saves her by changing her into a golden snail. Later in the story, the heroine will be saved again by a widowed fisherwoman who gives her refuge.

The belief in supernatural power is also shared by all represented Asian cultures as the belief appears in all sample folktales. It is inevitable that the tales with "transformation of man to snail" and "transformation of snail to man" motifs contain elements of supernatural belief; the story of transformation is in itself supernatural. Nevertheless, the popularity of these selected tales in Asia proves that the concept of the supernatural is widely accepted in the represented Asian cultures. People are enchanted by these tales and pass them on from one generation to the next. It could be said that the concept of the supernatural is ingrained in the way of life of the represented Asian cultures.

The belief in the Holy Spirit is evident in Sung Tong, Snail Millionaire, and Golden Snail. Sung Tong originates in Suwanna Sankha jataka in Pannas Jataka, which is the apocryphal Jataka that mimics the canonical Buddhist Jataka. Where the canonical Jataka relates the lives of Bodhisattvas the former births of Buddha - Suwanna Sankha Jataka in Pannas Jataka was written separately and added later to the Jataka cycle. In Snail Millionaire, the hero is born to a childless couple after they pray for the gift of a child. Praying for conception is a common practice in Asian culture; it is indeed a part of Asian identity as it is still a common practice in Asia today. There are many temples and sites in Asia that house idols and images for child conception, and these places are still highly popular among Asian tourists. Some of these sites include Putuo Shan Island in China with the child granting Guan Yin, Repulse Bay in Hong Kong with Baby Buddha, and Kotoku Temple in Japan with Daibutsu (Amida Nyoyurai) [18].

Male dominance is also an important social value, especially in Sung Tong, Snail Prince, and Snail Millionaire. The protagonists in all these stories are male heroes. In Sung Tong of Thailand and Snail Prince of Myanmar, the protagonists have to be male as both tales reflect Theravada Buddhist Teaching which favors male dominance in society [19]. The Bodhisattvas in the Jataka must always be male as they are believed to be the former births of Buddha. In Snail Millionaire, a childless couple prays to god for a child, and god responds by blessing them with a "son". A male child is more favored by Japanese parents as men are expected to work and obtain wealth for the family [20]. Male dominance is indeed a part of Japanese identity as reflected in this folktale.

Inner virtue appears in each of the sample folktales except for Golden Snail of Indonesia. In these tales, the protagonists are associated with snails. Snails are never considered as valuable as they can be found everywhere in Asia, especially in rice fields and swamps. Snails in these folktales represent inner virtue behind the physical appearance, and virtue is supposed to be valued above the physical world. Golden Snail of Indonesia does not emphasize inner virtue; rather, it emphasizes social class and the value of "gold" above other elements. "Gold" is therefore appropriate for the status of the heroine who is a princess. Although she is transformed into a snail, this high-born snail is still protected by a golden shell. In the case of Sung Tong, the name of the hero signifies "the golden conch", but the conch shell in this tale has nothing to do with gold. The word "gold" is added only because the hero bathes himself in a pond of gold later in the story. Sung Tong is a tale of inner virtue as the hero's appearance causes him to be banished from the kingdom. The King only perceives the bizarre appearance of his son so he refuses to look closer and see the potential of his new-born son.

The roles of women and children are evident in Snail Lady, River Snail Girl, Golden Snail and Sung Tong. The protagonists of these tales are either women or children hiding in the shell. These women and children protagonists leave the shell to conduct household chores. This behavior of the protagonists, reflects how Asian society expects women to stay at home as housewives, in contrast, men are expected to act as leaders and deal with the world outside the domestic sphere [21]. In the society of the time, when the stories originated, women were often expected to be submissive and to avoid showing themselves in society thus they were often perceived as almost "invisible." The plots of Snail Lady and River Snail Girl are similar. The female protagonists who are hiding in the snail shell were found by young men on their way home. The young man took the snail that he found home and put it in a jar. The following day when the young men went to work, the female protagonists come out of the snail shell to clean the house and prepare food. In Golden Snail, the princess who was cursed does the same thing for a poor widow who gives her refuge. Subsequently, the young men/widow found out that the snail shell was occupied by an enchanted woman. They destroyed the shell, thus preventing the woman from returning to the shell. The woman eventually married the young man. In a case of Golden Snail, the woman became an adopted daughter to the widow. The Prince eventually found her and took her and the widow to his palace.

The protagonist of Sung Tong must be male because of its origin in the Buddhist Jataka. However, it is only while the hero is a child that he is expected to perform domestic duties. Later, as he grows up, he performs other tasks outside the house. In the past, Asian cultures did not expect men to perform domestic duties. In Sung Tong, the hero only performs domestic tasks as a child. In the story, the protagonist voluntarily performs household duties to help his mother.

All the seven cultural values mentioned above can be ranked in terms of prominence according to Table III. Based on Table III, the rank of prominent cultural values is taken from the sample Asian folktales. The results according to the table are as follows:

1) Supernatural Beliefs (SB)

2) Gratitude (GT)

3) Good Karma (GK) 
4) Holy Spirit (HS) / Male Dominance (MD)

5) Inner Virtue (IV) / Role of Women and Children (WCh)

The three most prominent cultural values according to the selected folktales are Supernatural Beliefs (SB), Gratitude (GT) and Good Karma (GK).

The research outcomes in Table II, III, and IV might be potential data that may be relevant to other social sciences such as education, advertising and tourism. In education, stories are an excellent way of teaching children social concepts. Children often understand social values and concepts better if they are presented in the form of stories. In advertising, an understanding of important social values can help companies to create advertising for products that conform to these values and concepts. In tourism, a new form of cultural tourism has evolved where tourists are taken to places where traditional stories are told and the visitors are given an understanding of the host culture.

\section{CONCLUSION}

According to the study of sample Asian folktales, there are 7 cultural values that appear in these tales, namely, Gratitude, Good Karma, Supernatural Beliefs, Holy Spirit, Male Dominance, Inner Virtue and Role of Women and Children.

In general, the selected sample folktales share a similar motif, in their relation to snails. They also share many values, some of which are the shared by all represented Asian cultures. A study of these shared values helps us to understand the characters and perspectives of Asian people and Asian way of life. The outcomes reveal that the most prominent cultural value according to these tales is supernatural beliefs, followed by gratitude and good karma, respectively. An understanding of these values and the stories that they are represented in can be of value in other social sciences such as education, advertising and tourism as mentioned above.

\section{REFERENCES}

[1] H. Kim, "The role of folktales today," Telling Tales from Southeast Asia and Korea: Teacher's Guide, 2010, p. 2.

[2] H. L. Amali, "The function of folktales as a process of educating children in the $21^{\text {st }}$ Century: A case study of Idoma folktales," in Proc. $21^{\text {st }}$ Century Academic Forum Conference Proceedings, 2014, pp. 89-90.

[3] S. Thompson, The Folktale, New York, U.S.A.: The Dryden Press, 1951, p. 6.

[4] S. Thompson, Motif-Index of Folk-Literature, Bloomington, U.S.A.: Indiana University Press, 1885, p. 26.

[5] O. Suwanpratest, "Hiding in the shell: A comparative study of thai folktale "sang thong," in Proc. Annual Symposium on Management and Social Science (ASMSS), Seoul, Korea, 2014, pp. 378-385.
[6] K. M. Roebl, "Using children's literature to promote cultural diversity and interest," in Popular Culture and Its Changes, K. Cheng, ed. Taiwan: St. John's University, 2013, p. 66.

[7] P. Dhillon, "A survey of cultural values: Is a universally ethical financial system possible?" Seven Pillars Institute, Moral Cents, vol. 2, 2013.

[8] S. H. Peow, "Malaysian Chinese stories of hard work: Folklore and Chinese work values," IJAPS, vol. 11, no. 2, 2015, pp.1-6.

[9] S. Thompson, Motif-Index of Folk-Literature, Bloomington, U.S.A.: Indiana University Press, 1885 , pp. 26-35.

[10] S. C. Han, Korean Folk and Fairy Tales, $3^{\text {rd }}$ Ed., Seoul, Korea: Hollym Crop, 2011, pp. 104-107.

[11] P. C. R. Chaudhury, Folk Tales of Thailand, London, U.K.: Macmillan, 1990, pp. 49-56.

[12] S. M. Lwin, Narrative Structures in Burmese Folk Tales, New York, U.S.A.: Cambria Press, 2010, pp. 45-47.

[13] A. Muakhir, Kumpulan Cerita Rakyat: The Most Popular Indonesian Folk Tales, Jakarta, Indonesia: Serambi, 2013, pp.1-30.

[14] H. Giskin, Chinese Folktale, Lincolnwood: NTC, 1997, pp. 62-64.

[15] Y. Vorasingha, A Snail Millionaire. Interview, July 2014.

[16] A Snail Millionaire. [Online]. Available: http://www.geocities.co.jp/HeartLand-Gaien/7211/tanishi.html.

[17] Urban dictionary. [Online]. Available: http://www.urbandictionary.com/define.php?term=karma

[18] Kwamchua Tang Dan Kap Sathanthee 'Khor Look' Soot Hit. [Online] Available:

http://www.manager.co.th/Family/ViewNews.aspx?NewsID=9530000 164258

[19] R. G. Baker and F. J. Baker, "Cultural values in Thailand and Mexico: oral traditions, folk tales, and proverbs east and west," The Cal Pioly Pomona Journal of Interdisciplinary Studies, fall 2002, p. 104.

[20] K. M. Roebl, "Using children's literature to promote cultural diversity and interest," in Popular Culture and Its Changes, K. Cheng, ed. Taiwan: St. John's University, 2013, p. 70.

[21] J. O. Zuckerberg, Gender in Transition: A New Frontier, New York and London, 1989, p. 49.

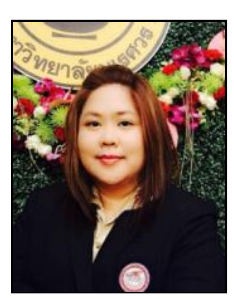

Onusa Suwanpratest was born in Thailand. She received her B.A. and M.A. degrees in Thai language and literature from Faculty of Arts at Chulalongkorn University, Thailand. She received honory support to pursue higher education from the Program Strategic Scholarships for frontier research network for the Joint Ph.D. Program from the Commission on Higher Education, Thailand. She received her Ph.D. in folklore from the Faculty of Humanities, Naresuan

University, Thailand.

Her Ph.D. dissertation focused on King Naresuan, a Great King in Thai history, which was published as a book: King Naresuan the Great : the Dynamic Power Behind the Nation (Bangkok, Thailand: Amarin Printing and Publishing, 2009) funded by the Kingkeo Atthakara Foundation. Since then, Dr.Suwanpratest has worked as a faculty member in the Department of Literature and Folklore, Faculty of Humanities, Naresuan University, Thailand. Her main focus is on comparative literature and folklore. She has received the honor of Outstanding Faculty staff in Folklore in 2010. She was invited as a visiting professor to teach in "ASEAN Folklore" during Asia Summer Program 2013 at Dongseo University, Busan, Korea. In 2015, she was chairman of the 1st Folklore conference hosted by Department of Literature and Folklore, Faculty of Humanities on the occasion of the 10th anniversary of the Folklore Program and the 25th anniversary of Naresuan University. 